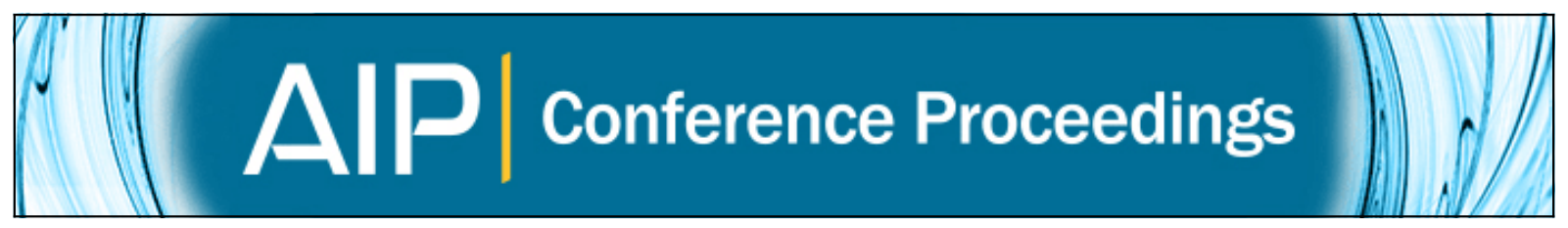

\title{
Women Physicists in Canada
}

Adriana Predoi-Cross, Roby Austin, Sampa Bhadra, Janis McKenna, Li-Hong Xu, and Michael Steinitz

Citation: AIP Conference Proceedings 1119, 95 (2009); doi: 10.1063/1.3137925

View online: http://dx.doi.org/10.1063/1.3137925

View Table of Contents: http://scitation.aip.org/content/aip/proceeding/aipcp/1119?ver=pdfcov

Published by the AIP Publishing

Articles you may be interested in

Bright and Not-So-Bright Prospects for Women in Physics in China-Beijing

AIP Conf. Proc. 1119, 97 (2009); 10.1063/1.3137926

Women Physicists in Turkey: 2002 to the Present

AIP Conf. Proc. 1119, 183 (2009); 10.1063/1.3137766

Women and Physics Research in Italy

AIP Conf. Proc. 1119, 126 (2009); 10.1063/1.3137735

Women in Physics in Estonia: Many Duties, One Life

AIP Conf. Proc. 1119, 114 (2009); 10.1063/1.3137728

Women in Physics in Egypt: The Status and Needs of Female Physics Students

AIP Conf. Proc. 1119, 111 (2009); 10.1063/1.3137726 


\title{
Women Physicists in Canada
}

\author{
Adriana Predoi-Cross ${ }^{\mathrm{a}}$, Roby Austin ${ }^{\mathrm{b}}$, Sampa Bhadrac, Janis McKenna ${ }^{\mathrm{d}}$, \\ Li-Hong $\mathrm{Xu}^{\mathrm{e}}$, and Michael Steinitz $\mathrm{f}^{\mathrm{f}}$ \\ ${ }^{a}$ University of Lethbridge, Lethbridge; ${ }^{b}$ Saint Mary's University, Halifax; ${ }^{\circ}$ York University, Toronto; \\ ${ }^{d}$ University of British Columbia, Vancouver; ${ }^{e}$ University of New Brunswick, Saint John; \\ ${ }^{f}$ St. Francis Xavier University, Antigonish
}

\begin{abstract}
In recent years the overall climate for women in academia in Canada has improved. Efforts are being made to attract girls to science at a young age. The enrollment of women across undergraduate and graduate programs in the physical sciences has increased gradually in the past decade, with a sharp increase at the graduate level. In light of a large number of upcoming retirements in academic positions, the presence of women in academia will continue to grow, supported by efforts to ensure equity in academia made by government agencies, academic institutions, and faculty associations.
\end{abstract}

Keywords: women in academia, Canada, undergraduate and graduate programs PACS: 01.40.Fk, 01.50.My, 01.50.Rt, 01.85.+f, 01.40.E

There is strong evidence that at the national level the overall climate for women physicists both in academia and industry has improved over the past decade in Canada. Organizations such as the Canadian Association of University Teachers (CAUT) are actively making efforts to minimize the current socioeconomic and professional gaps between women and men. CAUT is also trying to ensure that women in academia at all professional levels are offered equal opportunities with their male colleagues.

At the institutional level, in recent years several Canadian physics departments have undergone external critical assessments of the climate and environment for women in their departments. As a consequence, a friendly, open, invigorating, and welcoming climate toward women colleagues has been established and maintained. Some universities have made great strides and have three or four female faculty members in their physics departments. Unfortunately, across the country we still have many physics departments that have no women faculty members or have hired the first woman faculty member after over 25 years of academic activity!

\section{ATTRACTING GIRLS TO PHYSICS}

Numerous Canadian academic institutions and nonprofit organizations are making efforts to generate interest in science and physics at an early age, preferably before secondary school. Such programs run year round or are structured as girls-only summer camps hosted by universities. Activities are carefully selected to ensure that the participants have a large variety of opportunities to help them see the connections between science and everyday life, to help the participants to gain confidence in their science achievement, and ultimately to encourage their enrollment in future science courses. The Canadian Association for Girls in Science is an example of organization with chapters across the country that fosters early scientific literacy through a variety of diverse, fun activities such as "the physics of music," or "the chemistry of cooking." The Techsploration program running in Nova Scotia is one such example where role models well matched for the age group of the students interact with girls and try to stimulate their interest in and enjoyment of science.

Academic units across Canada also support the local schools in their efforts to attract girls to physics through a variety of outreach programs such as science fairs. For example, in Alberta girls represent more than $60 \%$ of the participants in local science fairs. In the Science Olympics, part of the Regional Science Fair in Alberta, up to $75 \%$ of the participants were girls! Clearly girls are interested in science and it is up to us to design activities to generate and maintain their interest in physics and in science in general. 


\section{CLIMBING UP THE LADDER AND NARROWING THE GENDER GAP IN CANADIAN ACADEMIA}

The Equity Review released in 2008 by the CAUT has shown a firm upward trend in the enrollment of women in higher education at the college, undergraduate, and graduate levels. At the graduate level in physical sciences we have experienced increases of $90 \%$ in the enrollment of women compared with 1992. Regardless of the "feminization of universities," the number of female students in physical sciences still lags behind the number of male students. Aside from small regional differences, women continue to be underrepresented in applied sciences.

Over the past 40 years the number of Canadian universities has increased from 30 to over 75 . In parallel with this steady growth, there has been an improvement in the status of women faculty across the country. Unfortunately, only $10 \%$ of all women faculty members teach in applied sciences, compared with a third of all men. While a sizable difference in the proportions by gender at the same academic level remains [1], the difference has fallen dramatically and the trend appears to be continuing. However, at the rank of full professor, and at the highest levels of university administration, women continue to be underrepresented. By 2006, the most recent year for which we have data, $11 \%$ of physics faculty were women and $6.3 \%$ of full professors of physics are women.

\section{THE "MATERNAL WALL" IN CANADIAN ACADEMIA}

In spite of numerous efforts to reduce the gender differences in institutions across Canada, in recent years several feminist studies have pointed out that Canadian women that have higher education may not encounter gender discrimination until they encounter the so called "maternal wall" that hinders advancement in their professional careers [2]. This is mostly because traditionally in our country women are the ones who do most of the domestic work and are in charge of household management, child care, and elder care.

The cumulative effect of all these factors is that professional mothers simply are unable to find the overtime hours that are often both expected and required for advancement and success in their profession. Professionals who are mothers often find themselves "mommy-tracked" both financially and on the professional advancement scale. Sadly [3], it has been shown that the pay gap between young or middle-aged mothers and women of the same age who have no children is now larger than the wage gap between men and women from the same age group [4]. In Canada, organizations such as the Association for Research on Mothering, founded in Toronto at York University, are making efforts to find strategies to help mothers cope with the "maternal wall" in academia.

\section{CONCLUSION}

In recent years Canada has seen an increase in the number of women at all academic levels in applied physical sciences. Empathy and a good understanding of all challenges faced by women in these disciplines will make the equity initiatives a success. The trends observed in recent years will continue if the academic institutions and their faculty associations work together with our government agencies with the goal of obtaining equity at all levels in academia.

\section{ACKNOWLEDGMENTS}

Partial financial support for the Canadian team members was provided by the Canadian Association of Physicists. A. Predoi-Cross is grateful for financial support from the Dean of Arts and Sciences and the Faculty Association of University of Lethbridge. R. Austin acknowledges support from Saint Mary's University. L.H. Xu acknowledges partial financial support from the University of New Brunswick in Saint John. M. Steinitz acknowledges support from St. Francis Xavier University and the National Research Council of Canada Research Press.

\section{REFERENCES}

1. A.R.R. Margulis, The Road to Success: A Career Manual-How to Advance to the Top, Academic Press, 2006.

2. A. O'Reilly, Rocking the Cradle, Demeter Press, 2006.

3. H.A. Cummins, Women's Studies International Forum 28: 222-231. 2005.

4. A. Crittenden, The Price of Motherhood: Why the Most Important Job in the World is Still the Least Valued, Holt Paperbacks, 2002. 